\title{
A MATEMÁTICA DO KAMAL: UMA POSSIBILIDADE DE INSERÇÃO NO ENSINO
}

\author{
Ana Carolina Costa Pereira ${ }^{1}$, Antonia Naiara de Sousa Batista $^{2}$ \\ ${ }^{1}$ UUniversidade Estadual do Ceará \\ ${ }^{2}$ Instituto Federal de Educação, Ciência e Tecnologia do Ceará - IFCE \\ <carolina.pereira@uece.br>, <antonianaiarabatista@yahoo.com.br>
}

DOI: $10.21439 /$ conexoes.v10i4.1141

\begin{abstract}
Resumo. O referido texto versa sobre o entendimento da construção de instrumentos antigos e a sua articulação com o ensino e a aprendizagem da Matemática, tendo a História da Matemática como elemento norteador para a aprendizagem da Ciência em questão. Essa união possibilita a visão da aplicabilidade de conceitos matemáticos que podem ser utilizados, como uma ferramenta didática na Educação Básica. Desse modo, tal artigo tem o intuito de apresentar a compreensão acerca da articulação entre a história, o ensino e a aprendizagem da Matemática por meio do Kamal, no qual serão evidenciados conceitos matemáticos, bem como as suas potencialidades e limitações para o uso no Ensino Fundamental. O mesmo também tem o objetivo de suscitar em sala de aula a necessidade de se utilizar as pesquisas nessa área, principalmente, as que proporcionem diferentes recursos metodológicos. Um exemplo que pode ser inserido ao meio escolar por meio do uso dos instrumentos matemáticos históricos que foram importantes no desenvolvimento da ciência.
\end{abstract}

Palavras-chaves: Instrumento Náutico. Kamal. Ensino de Matemática. Formação inicial de professores de Matemática.

\begin{abstract}
The text deals with understanding the construction of old instruments and their articulation with the teaching and learning of mathematics, and the history of mathematics as a guiding element for Science learning in question. This union allows the view of the applicability of mathematical concepts that can be used as a teaching tool in basic education. Thus, this article aims to provide an understanding about the link between history, and the teaching and learning of mathematics by Kamal, which will be evidenced mathematical concepts and their potential and limitations for use in Elementary and Middle Schools. The article also aims to raise in class the necessity of using the research in this area, especially those that provide different methodological resources. This is an example that may be inserted into the school environment through the use of historical mathematical instruments that were important in the development of science.
\end{abstract}

Keywords: Nautical instrument. Kamal. Mathematics Teaching.

\section{INTRODUÇÃo}

Nessas últimas décadas a História da Matemática tem sido apontada como um recurso pedagógico favorável à construção das noções matemáticas aos discentes. Segundo Mendes (2006)p. 84 "o uso da História da Matemática como recurso pedagógico tem como principal finalidade promover um ensino-aprendizagem de matemática que permita uma ressignificação do conhecimento matemático produzido pela sociedade ao longo dos tempos". Isso ainda pode ser complementado pelo caráter motivador e gerador de saberes que a História da
Matemática traz quando aplicada de forma satisfatória.

Essa aplicação está associada ao modo como a história é problematizada em sala de aula, pois ela é pensada como uma alternativa para superar dificuldades encontradas no ensino e na aprendizagem da matemática valorizando a investigação, a curiosidade científica, as habilidades matemáticas e a autonomia intelectual do discente.

$\mathrm{Na}$ intenção de integrar a História com atividades matemática em sala de aula, algumas possibilidades podem surgir, principalmente no que se refere a articula- 
ção do conhecimento matemático direcionado ao aluno da Educação Básica. Uma proposição, nesse sentido, pode ser o estudo de instrumentos históricos utilizados para efetuar medidas. Assim como, por exemplo, o conhecimento a respeito do que aconteceu ao longo dos séculos XIV a XVII, período o qual colaborou significativamente para o desenvolvimento, tanto da História da Matemática, quanto para as demais ciências.

No Brasil, a articulação entre a história, o ensino e a aprendizagem da matemática utilizando dados e fatos históricos são abordados pelo pesquisador Saito e Dias (2011), Saito (2013), Saito (2014) que estuda um conjunto de obras que tratam sobre a construção e uso de instrumentos matemáticos. Segundo ele, o uso de tal estratégia de ensino, propicia um retorno ao passado como forma de reconstituir conceitos matemáticos atuais, facilitando o processo de aprendizagem dos educandos. Assim como, no sentido de, "fornecer a reconstrução das ideias matemáticas já pré-concebidas e sedimentadas pelos discentes, fazendo-o (re)significar o objeto matemático" (SAITO, 2014) p. 29.

Outro fato que contribui para um ensino pautado no que o autor menciona, é a possibilidade do contato físico por parte dos discentes sobre os artefatos históricos, sobretudo, aqueles construídos por eles, assim como a visualização e a aplicação do conteúdo estudado por meio de situações práticas. Isso provoca nos educandos a busca acerca das respostas dos "porquês" ou "para que serve isso" algo necessário a ser problematizado no cotidiano escolar.

Bussi (2000) também ressalta que o uso da História da Matemática pode entrar como atividade em sala de aula, como fator investigador em cópias de instrumentos antigos e outros artefatos, reconstruídos com base em fontes históricas, exemplificando no campo da Aritmética, Álgebra, Geometria e Matemática Aplicada.

Nesse sentido, o estudo de conceitos - sejam eles matemáticos ou não - por meio de instrumentos antigos, possibilita ao aluno a compreensão acerca dos aspectos sociais, políticos, culturais e econômicos que são relacionados ao objeto investigado, permitindo que ações interdisciplinares, por exemplo, possam configurar no ambiente escolar como oportunidades de demonstrar a relação entre as demais disciplinas da matriz curricular e a Ciência Matemática. Tal interação pode amenizar a aversão que muitos alunos têm a respeito dessa área do conhecimento.

O desafio nesse sentido é: "ampliar o foco de análise e contextualizar os instrumentos em seus devidos quadros conceituais, de modo a compreender a complexa trama da relação entre teoria, instrumento e experimento" (SAITO, 2012)p. 5. Nesse sentido, em deter- minadas situações didáticas, essas três dimensões são tratadas, de forma superficial, pois de acordo com os níveis de ensino, determinados elementos conceituais históricos da matemática ainda precisam ser amadurecidos, para assim serem tratados ao longo das aulas.

A contextualização entre a história e o ensino no processo de reconstituição, se faz necessária, pois: “a História da Matemática é tomada como ponto de partida para o discente resignificar os conceitos matemáticos e levantar discussões epistemológicas que seriam relevantes para o ensino e a aprendizagem da matemática" (SAITO, 2014) p. 28.

Nesse sentido, quando vislumbramos o potencial didático/pedagógico do estudo de instrumentos antigos, possibilitamos uma aproximação do conhecimento matemático envolvido no processo de construção física (instrumento por ele mesmo); cálculo e marcação das medidas do instrumento; e a aplicação utilizando os conceitos já estudados.

Para o estudo aqui proposto, não utilizamos documentos originais da época o qual nosso instrumento, o Kamal, foi fabricado pela 1a vez, visto que, ele é um artefato do século XV de origem árabe e indiana, que foi apresentado ao navegador Vasco da Gama em sua primeira viagem à Índia pelo árabe Ahmad Ibn-Majid. Todavia, utilizamos como referência o livro de Manuel Pimentel, Arte de navegar, de $1762{ }^{1}$

Desse modo, para nosso estudo, seguimos a proposta apontada por Saito (2014)p. 28 indicando que os documentos estudados devem ser

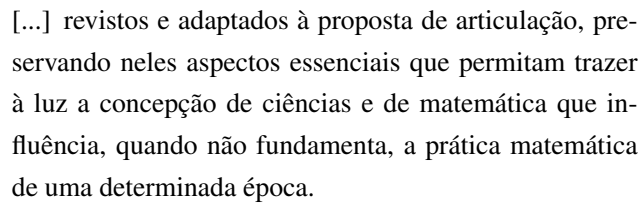

O tratamento didático do material foi realizado para que os discentes se sentissem imersos no processo histórico de construção do Kamal. Porém, se advertiu que fazer uma reconstituição exata é quase impossível, "visto que não temos notícias dos conhecimentos e técnicas mobilizados por artesão na sua construção" (SAITO, 2014)p. 28.

O material didático confeccionado foi elaborado de modo a ajudar o discente na proposta de uso do instrumento para a aquisição de conceitos matemáticos. A História da Matemática foi utilizada como forma de gerar uma reflexão entre os conteúdos envolvidos na construção do instrumento Kamal. A possível inserção na

\footnotetext{
${ }^{1}$ Tentamos adquirir o Livro de Marinha de André Pires, 1541 citado por Pimentel como uma das primeiras obras que descrevem o Kamal, mas não obtivemos êxito.
} 
educação básica, além de refletir sobre alguns conceitos trigonométricos de modo a levantar outras questões sobre o tema, visualizando algumas práticas antigas na realização das medições.

Desse modo, tal artigo tem o objetivo de apresentar um estudo sobre a compreensão dos alunos de licenciatura em Matemática da UECE, a respeito da articulação entre a história, o ensino e o aprendizado da matemática por meio do uso do Kamal, bem como dos conceitos trigonométricos relacionados a ele. Para isso, primeiramente apresenta-se o instrumento Kamal, a matemática envolvida e seu uso, para posteriormente discutir os resultados obtidos a partir da aplicação de um curso para a formação inicial de professores sobre esse instrumento.

\section{KAMAL, AS TÁBUAS DA ÍNDIA OU TAVOLE- TAS}

Na tentativa de unir a teoria com a prática escolar na disciplina de matemática fez-se um levantamento das possibilidades de aplicação de conteúdos de forma a permitir ao aluno da educação básica vivenciar a produção de conhecimento por meio da construção de instrumentos antigos, sejam eles astronômicos, matemáticos, ópticos, ou de agrimensura.

Dentre os instrumentos que tem uma construção física simples e material de baixo custo, a Tábua da Índia ou Tavoletas, também conhecida por Kamal ou alKemal (que significa em árabe, a "linha guia"), permite o estudo de conteúdos aritméticos e geométricos que podem oportunizar ao aluno vivenciar uma aplicação da Matemática.

A Tábua da Índia é uma espécie de Balestilha, menos rigorosa, porém de mais fácil transporte. Ela é um instrumento náutico de origem árabe e indiana, que surge inicialmente com o nome Kamal, que posteriormente fora utilizado por navios portugueses com a designação de Tavoletas da Índia ou Balestilha do Mouro. Foi apresentado ao navegador Vasco da Gama em sua primeira viagem à Índia pelo árabe Ahmad Ibn-Majid. Segundo Albuquerque (1972)p. 195:

\footnotetext{
Este dispositivo para a observação de alturas foi encontrado pelos marinheiros da primeira armada de Vasco da Gama nas mãos dos pilotos do Índico, trazido para a Europa em 1499, experimentado por homens do mar e por cosmógrafos, e por fim adaptado na náutica portuguesa sob a designação de tavoletas da Índia ou balestilha do mouro $[\ldots]$.
}

Sua principal função era determinar a altura das estrelas em relação à linha do horizonte, mais especificamente utilizando a estrela Polar como ponto de referência, pois segundo Pinto (2010)p. 11, "uma vez que a altura da Estrela Polar era, aproximadamente, a latitude do lugar, quando viajavam no hemisfério norte, tinham aí um processo fácil de se localizarem".

O Kamal é constituído por uma tábua retangular de madeira com um orifício no centro, no qual se passa um cordel em que são dados vários nós, que correspondem à altura da Estrela Polar, ou seja, a latitude que corresponde a um determinado porto mais frequentado naquela época. Para se chegar ao local desejado navegavase pela costa da Arábia até encontrar a latitude equivalente a localização do porto de destino e começava-se a velejar para o leste no intuito de se aproximar do território escolhido (PINTO, 2010).

Um exemplar de Kamal 1 1 pode ser encontrado no museu etnográfico de Hamburgo, na Alemanha, cuja placa de madeira tem $6,65 \mathrm{~cm}$ altura por $4,8 \mathrm{~cm}$ de largura e $4 \mathrm{~mm}$ de espessura com um cordão de 16 nós.

Para estimar a altura de uma estrela por este instrumento segura-se a tabuinha com uma das mãos e o cordel com a outra, estende-se para frente um braço com a tábua na mão, retesando-se o cordel, seguro pelo extremo na outra mão ou entre os dentes. A tabuinha pode colocar-se com o lado menor, ou o maior, vertical, conforme a grandeza do ângulo a medir, e aproxima-se ou afaste-se do olho do observador até que o horizonte $\mathrm{H}$ se veja pelo lado inferior, e a estrela E pelo lado superior, do retângulo de madeira Figura2.

Os nós do cordel irão passando na outra mão que conservará o cordel teso. A grandeza do ângulo observado dependerá do nó que ficar seguro nesta mão. Assim, quanto maior fosse o ângulo, mais se aproximava a placa de madeira, menor seria a porção de cordel entre ela e os dentes do observador, e maior a parte do cordão que sobrava caída para baixo. Então, o Kamal é uma balestilha em que o virote é substituído pelo cordel, e os traços de graduação do virote pelos nós. A tabuinha serve de soalha e fornece até duas soalhas, conforme o lado que se puser ao alto. O Kamal é, pois, uma espécie de balestilha, menos rigorosa, mas de mais cômodo transporte.

As Tábuas da Índia tinham dois tamanhos, um pequeno e um grande. $\mathrm{O}$ tamanho pequeno era conhecido como "Tavoleta pequena" que utilizava ângulos de 5 a 14 graus. (SILVA, 1924)p. 367 ainda ressalta que

\footnotetext{
[...] deves saber que quando quer que tomares altura da estrêla pela tavoleta pequena tereis aviso que ao fazer da conta heis de meter cinco e com êles, e com os nós que estiverem dos dentes para baixo, tirando ou metendo os que a estrêla está abaixo.
}

A tábua tinha altura pequena, e era atravessada no centro por um cordão de 10 nós. Segundo Silva (1924)p. 367 - 368: 


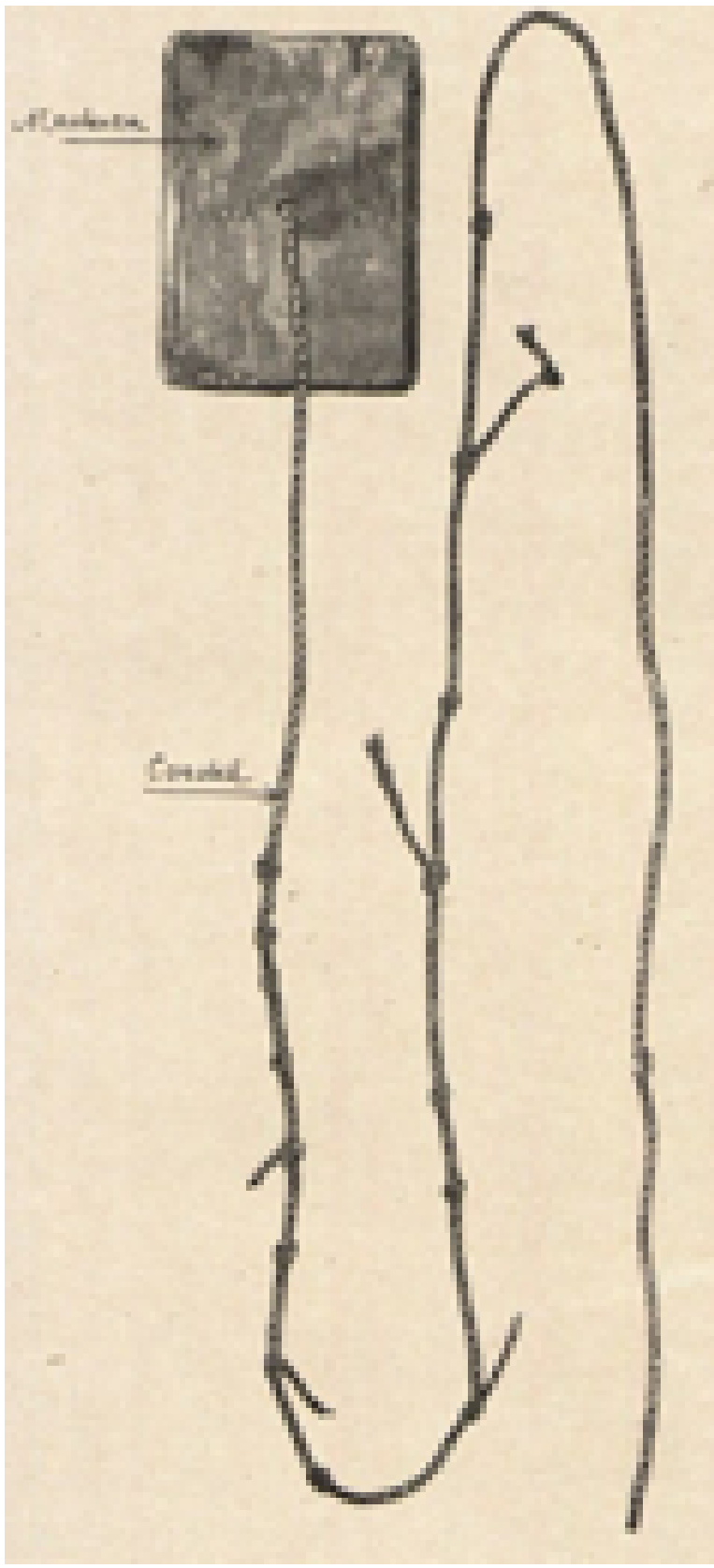

Figura 1: Kamal exposto do Museu de Hamburgo.

Fonte: SILVA 1924 ,p. 362

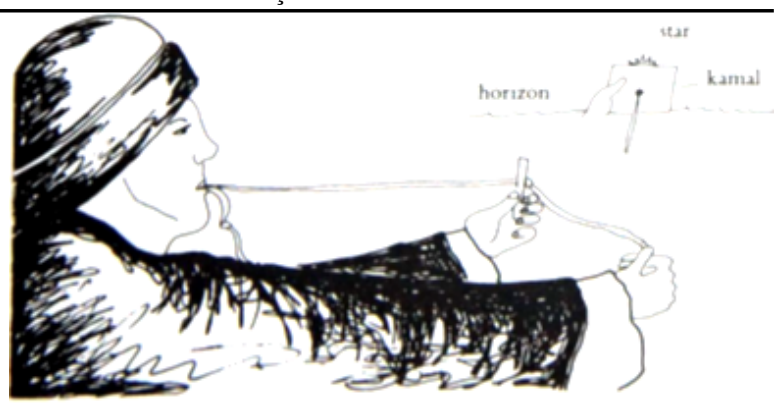

Figura 2: Utilização da Tábua da Índia.

Fonte: FISHER 1994)p. 19

Quando, preso nos dentes o último nó, o mais afastado da placa de madeira, e retesado o cordão com o braço estendido, se via a estrela por cima, e o horizonte por baixo, segurava-se o penúltimo nó entre os dentes, pendia um nó abaixo deles, e o ângulo era 6 graus $(5+1)$, e sucessivamente. Vê-se que, tendo nos dentes o nó correspondente ao ângulo a medir, se contava o número de nós caídos para baixo deles, e este número, junto a 5 , dava os graus de altura da estrela.

As "tavoletas grandes" possuíam maiores dimensões e utilizava graus maiores que 15 , de forma que o "preso entre os dentes o último nó, o da ponta do cordel, o ângulo medido era de 15 graus. Para ângulos maiores, pendia-se nos dentes outro nó, e o número dos que pendiam abaixo dos dentes, junto a 15, dava os graus de altura" (SILVA, 1924)p. 368.

Para a graduação dos nós eles utilizavam uma graduação em isbas 3 (unidade angular equivalente a $1^{\circ} 37^{\prime}$ ) A isba era usada pelos navegadores árabes no oceano Índico, na determinação das latitudes, media-se pondo o dedo na horizontal com o braço esticado. O termo Isba em árabe significa dedo, o que também correspondia a uma polegada.

A seguir, descreveremos a matemática utilizada na sua construção, no caso a tábua de madeira e o cordel.

\section{A MATEMÁTICA ENVOLVIDA NA CONSTRU- ÇÃO DA TÁBUA DA ÍNDIA}

A Tábua da Índia é constituída de um pedaço de madeira retangular, que pode ser substituiu por papel cartolina, e um barbante colocado em um orifício central fixada no retângulo. Para a tábua de madeira, fizemos

${ }^{3}$ A padronização da isba de $1^{\circ} 37^{\prime}$ é devido a menção dada por Albuquerque (1972)p. 198 utilizada pelo historiador contemporâneo Gabriel Ferrand que adotou esse valor. Porém em trabalhos de André Pires em seu Livro de Marinharia ele fixa a isba em $1^{\circ} 36^{\prime}$. 
uma réplica do Kamal tomando como referência a tábua citada por Silva (1924) encontrada no museu etnográfico de Hamburgo que tem $6,65 \mathrm{~cm}$ altura por $4,8 \mathrm{~cm}$ de largura e $4 \mathrm{~mm}$. Porém, para facilitar e diminuir os erros com as medidas, confeccionamos a peça de madeira (Figura 3) de 4 milímetros de espessura e de 70x50 milímetros.

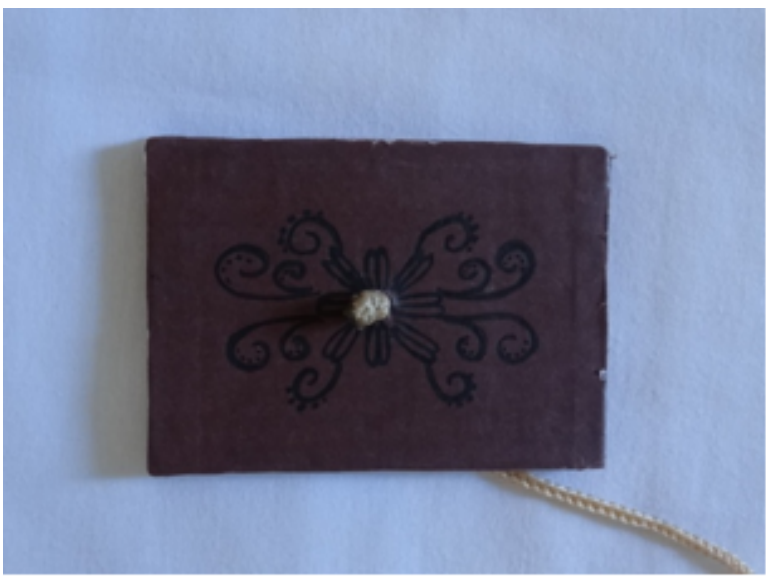

Figura 3: Tábua do Kamal (70x50 mm)

Fonte: Elaborada pela autora.

Para o cordel, utilizamos um barbante de tamanho aleatório, já que é importante a marcação dos nós. Segundo Rodrigues (2009, s/p):

\footnotetext{
O número de nós ao rectângulo de madeira dá-nos a quantidade de isbas que corresponde a esse afastamento, mas em sentido inverso, ou seja, se a cordel tiver catorze nós e estiver completamente esticada, um isba, corresponde a segurar o $13^{\circ}$ nó, restando um para que a corda fique completamente esticada, assim o número de isbas é medido através do números de nós que restam na corda ou fio, para a ter completamente esticada.
}

Para a localização dos nós, isto é, da determinação do ponto do cordel onde deve ser colocado o nó correspondente a cada latitude, consideramos um retângulo OPQR. Pelos segmentos PQ e OR são marcados os pontos médios A e B respectivamente. Traçando-se o segmento $\mathrm{AB}$, o ponto médio, $\mathrm{C}$, será o orifício central do retângulo (Figura 4).

Para a marcação dos nós no cordel, os povos antigos faziam uso de uma geometria simples, conforme mostraremos a seguir, utilizando-se de relações trigonométricas e semelhança de triângulos.

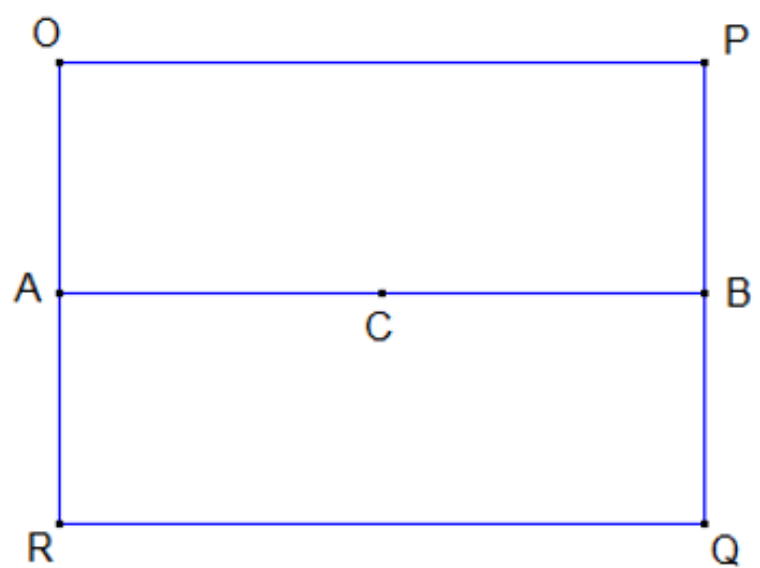

Figura 4: Tamanho real do Kamal confeccionado.

Fonte: Elaborada pela autora

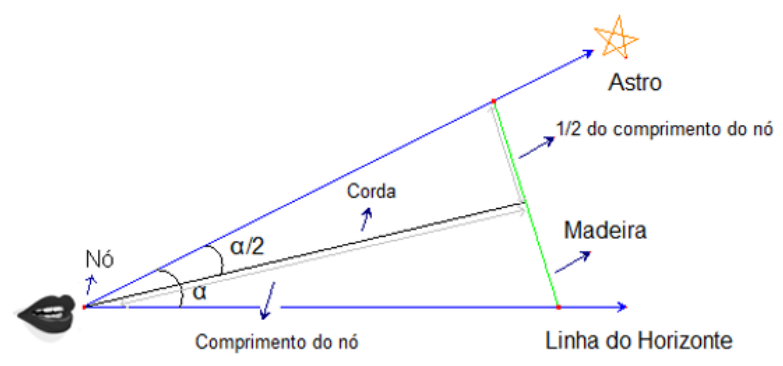

Figura 5: A geometria do Kamal.

Fonte: Elaborada pela autora.

Segundo Rodrigues (2009)p. 01: 
Admite-se que o ângulo entre o fio e a tábua é igual ao ângulo entre a linha de visão do equador e do astro. Se não o for, o mesmo utilizador cometerá sempre o mesmo erro, e no conjunto das observações que faz com esse instrumento repete de forma sistemática os mesmos erros

Para encontrarmos a distância do orifício central da tábua e os nós, iremos a princípio tomar o ponto $\mathrm{D}$ como o primeiro nó que será dado no cordel. Como $\mathrm{C}$ é ponto médio de $\mathrm{AB}$ e $\mathrm{CD}$ é bissetriz $\mathrm{CD}$, logo $\mathrm{CD}$ é também altura do triângulo ADB Figura 6 Logo, $\operatorname{tg}=(\alpha / 2)=$ $\mathrm{AC} / \mathrm{CD}$, ou seja, $\mathrm{AC}=\mathrm{AC} / \operatorname{tg}(\alpha / 2)$. Generalizando, o comprimento do nó é igual a $(1 / 2) \mathrm{AB} / \operatorname{tg}(\alpha / 2)$.

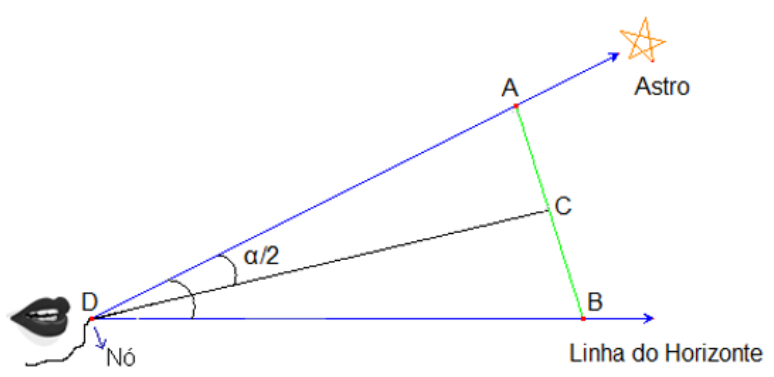

Figura 6: Calculando o comprimento do nó

Fonte: Elaborada pela autora.

Como mencionado anteriormente, o comprimento dos nós é dado pela fórmula: $(1 / 2) \mathrm{AB} / \operatorname{tg}(\alpha / 2)$. Agora devemos então encontrar o ângulo entre o cordel e a linha de visão. Gostaríamos de ressaltar que a unidade de medida árabe angular é denominada de isba que equivale a aproximadamente uma polegada. Uma isba é igual a $1^{\circ} 37^{\prime}$ ou $97^{\prime}$ ou $1,617^{\circ}$ ou $25,4 \mathrm{~mm}$ de polegada. Para facilitar iremos construir uma tabela com cada comprimento de nó, conforme Tabela 1

Para essa construção, utilizou-se como referência a estrela polar, de nome Polaris 4 , visível apenas no hemisfério Norte, visto que a construção foi realizada tomando como base o texto do português Manuel Pimentel, Arte de navegar, cujos cálculos foram feitos adotando como suporte a Estrela Polar, que no nosso hemisfério não é visualizada.

Dessa forma, percebe-se que na construção da Corda da Índia ou Kamal a Matemática possa ser aplicada, tornando-se possível explorar conteúdos estudados na Educação Básica. Atrelado a esses conteúdos matemáticos, o destaque aos elementos físicos e/ou astronômicos que oportunizam um aprendizado interdisciplinar ao aluno, contribui no fortalecimento das relações entre teoria e prática.
Tabela 1: Comprimentos para cada nó.

\begin{tabular}{|c|c|c|c|c|c|c|}
\hline & ISBAS & $\begin{array}{l}\text { Ângulo } \\
\beta=1 / 2 \alpha\end{array}$ & $\begin{array}{l}\text { Ângulos } \\
\text { em graus }\end{array}$ & Tag $\beta$ & $1 / 2(\mathrm{AB})$ & $\begin{array}{l}\text { COMPRIMENTO } \\
\text { DOS NOS }\end{array}$ \\
\hline $1^{\circ}$ nó & 1 isba & $\begin{array}{l}\beta=1 \cdot 1 / 2 \cdot 1,617 \\
\beta=0,8085\end{array}$ & $0^{\circ} 43^{\prime}$ & 0,014112 & $25 \mathrm{~mm}$ & $1771,5 \mathrm{~mm}$ \\
\hline $2^{\circ}$ nós & 2 isbas & $\begin{array}{l}\beta=2 \cdot 1 / 2 \cdot 1,617 \\
\beta=1,617\end{array}$ & $17^{\circ}$ & 0,02823 & $25 \mathrm{~mm}$ & $885,58 \mathrm{~mm}$ \\
\hline $3^{\circ}$ nós & 3 isbas & $\begin{array}{l}\beta=3 \cdot 1 / 2 \cdot 1,617 \\
\beta=2,4255\end{array}$ & $2^{\circ} 25^{\prime}$ & 0,04236 & $25 \mathrm{~mm}$ & $590,18 \mathrm{~mm}$ \\
\hline $4^{\circ}$ nós & 4 isbas & $\begin{array}{l}\beta=4 \cdot 1 / 2 \cdot 1,617 \\
\beta=3,234\end{array}$ & $3^{\circ} 14^{\prime}$ & 0,05651 & $25 \mathrm{~mm}$ & $442,39 \mathrm{~mm}$ \\
\hline $5^{\circ}$ nós & 5 isbas & $\begin{array}{l}\beta=5 \cdot 1 / 2 \cdot 1,617 \\
\beta=4,0425\end{array}$ & $4^{\circ} 02^{\prime}$ & 0,07067 & $25 \mathrm{~mm}$ & $353,75 \mathrm{~mm}$ \\
\hline $6^{\circ}$ nós & 6 isbas & $\begin{array}{l}\beta=6 \cdot 1 / 2 \cdot 1,617 \\
\beta=4,851\end{array}$ & $4^{0} 51^{\prime}$ & 0,084868 & $25 \mathrm{~mm}$ & $294,57 \mathrm{~mm}$ \\
\hline $7^{\circ}$ nós & 7 isbas & $\begin{array}{l}\beta=7 \cdot 1 / 2 \cdot 1,617 \\
\beta=5,6595\end{array}$ & $5^{\circ} 39^{\prime}$ & 0,099099 & $25 \mathrm{~mm}$ & $252,27 \mathrm{~mm}$ \\
\hline $8^{\circ}$ nós & 8 isbas & $\begin{array}{l}\beta=8 \cdot 1 / 2 \cdot 1,617 \\
\beta=6,468\end{array}$ & $6^{\circ} 28^{\prime}$ & 0,113369 & $25 \mathrm{~mm}$ & $220,52 \mathrm{~mm}$ \\
\hline $9^{\circ}$ nós & 9 isbas & $\begin{array}{l}\beta=9 \cdot 1 / 2 \cdot 1,617 \\
\beta=7,2765\end{array}$ & $7^{\circ} 16^{\prime}$ & 0,127686 & $25 \mathrm{~mm}$ & $195,79 \mathrm{~mm}$ \\
\hline $10^{\circ}$ nós & 10 isbas & $\begin{array}{l}\beta=10 \cdot 1 / 2 \cdot 1,617 \\
\beta=8,085\end{array}$ & $8^{\circ} 05^{\prime}$ & 0,142053 & $25 \mathrm{~mm}$ & $175,99 \mathrm{~mm}$ \\
\hline $11^{\circ}$ nós & 11 isbas & $\begin{array}{l}\beta=11 \cdot 1 / 2 \cdot 1,617 \\
\beta=8,8935\end{array}$ & $8^{\circ} 53^{\prime}$ & 0,15648 & $25 \mathrm{~mm}$ & $159,76 \mathrm{~mm}$ \\
\hline $12^{\circ}$ nós & 12 isbas & $\begin{array}{l}\beta=12 \cdot 1 / 2 \cdot 1,617 \\
\beta=9,702\end{array}$ & $9^{\circ} 42^{\prime}$ & 0,17097 & $25 \mathrm{~mm}$ & $146,22 \mathrm{~mm}$ \\
\hline $13^{\circ}$ nós & 13 isbas & $\begin{array}{l}\beta=13 \cdot 1 / 2 \cdot 1,617 \\
\beta=10,5105\end{array}$ & $10^{\circ} 8^{\prime}$ & 0,18553 & $25 \mathrm{~mm}$ & $134,74 \mathrm{~mm}$ \\
\hline
\end{tabular}

${ }^{4}$ A estrela mais luminosa da constelação da Ursa Menor. 


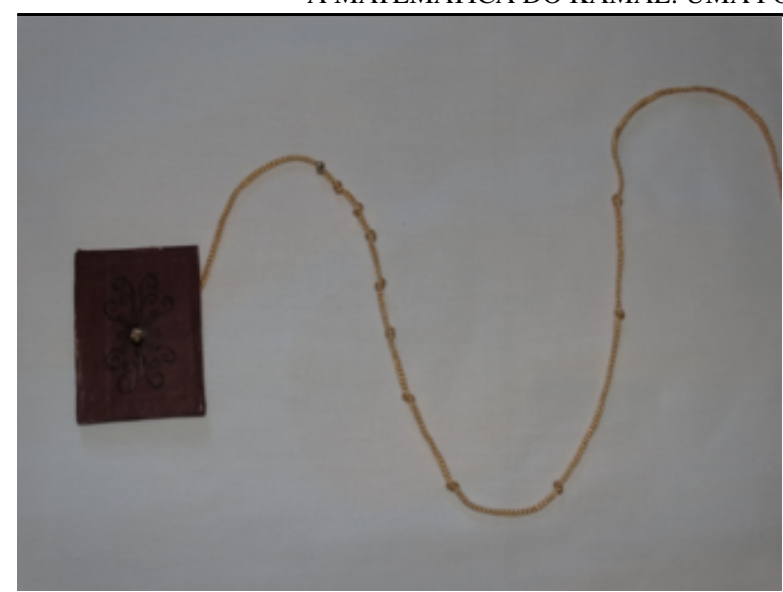

Figura 7: Tábua da Índia confeccionada, 11 nós.

Fonte: Elaborada pela autora.

\section{PROPOSTA PARA O USO DO INSTRU- MENTO KAMAL}

$\mathrm{Na}$ formação (inicial ou continuada) do professor de matemática as alternativas metodológicas ou mesmo recursos didáticos devem ser explorados com o intuito de complementar os estudos e práticas. Tal complementação pode ocorrer de forma gradativa no decorrer na graduação, ou como uma capacitação docente após a formação, por meio da educação continuada.

Nessa vertente, o Laboratório de Matemática a Ensino da Universidade Estadual do Ceará (UECE) em conjunto com o Grupo Pesquisa em Educação e História da Matemática (GPEHM) têm investido em cursos de extensão universitária como uma forma de ampliar o arcabouço teórico e didático do acadêmico e futuro professor de matemática, oportunizando o acesso a estudos que visam relacionar a teoria matemática com a construção de materiais concretos manipuláveis. Estabelece-se, portanto, uma parceria entre a História da Matemática e os instrumentos antigos de medição.

Vale ressaltar que nosso público alvo são os professores em processo de formação inicial e continuada, que desejam inovar métodos de ensino e técnicas utilizadas em sala de aula, por meio da utilização de instrumentos históricos de medição, como o quadrante náutico, a balestilha, o Kamal e a régua de cálculo.

Dentre esses instrumentos, o Kamal foi trabalhado em um curso de 20 horas com 28 discentes do curso de licenciatura em Matemática da UECE Figura 8. Nosso propósito era, a partir do curso, coletar dados que pudessem mostrar a percepção dos participantes em conhecer, praticar e aplicar esse instrumento no estudo de conceitos matemáticos e estimular que os participantes percebessem as potencialidades e limitações do instrumento Kamal.

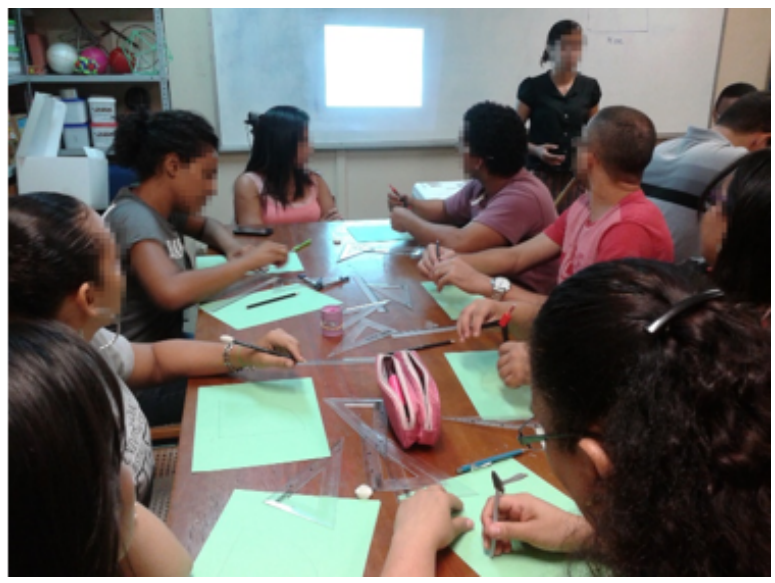

Figura 8: Participantes do curso de extensão sobre o Kamal.

Fonte: Arquivo da autora.

Dessa maneira, foram elaborados e aplicados préteste e pós-teste, gravações de áudio e vídeo, atividades de complementação de conteúdo para que posteriormente pudéssemos fazer uma análise.

O planejamento e a condução aconteceram no mês de julho de 2015. No Quadro 1 se apresenta a estrutura organizacional do cursd 5

Quadro 1: Planejamento e condução do curso.

\begin{tabular}{|c|l|l|}
\hline Data & \multicolumn{1}{|c|}{ Conteúdo } & \multicolumn{1}{|c|}{ CH } \\
\hline Aula 01 & $\begin{array}{l}\text { Uma proposta do uso de instrumentos históricos para } \\
\text { o ensino de Matemática }\end{array}$ & $4 \mathrm{~h} / \mathrm{a}$ \\
\hline Aula 02 & Um pouco da história de instrumentos matemáticos. & $4 \mathrm{~h} / \mathrm{a}$ \\
\hline Aula 03 & Conceitos iniciais de Astronomia. & $2 \mathrm{~h} / \mathrm{a}$ \\
\hline Aulas 04-07 & $\begin{array}{l}\text { A História, matemática e a construção física do Kamal. } \\
\text { Possível aplicaçãop. }\end{array}$ & $8 \mathrm{~h} / \mathrm{a}$ \\
\hline Aula 08 & $\begin{array}{l}\text { Discussões do uso do Kamal para o ensino da } \\
\text { Matemática: vantagens e desvantagens }\end{array}$ & $2 \mathrm{~h} / \mathrm{a}$ \\
\hline \multicolumn{2}{|l}{ Total de horas } & $\mathbf{2 0 h} / \mathbf{a}$ \\
\hline
\end{tabular}

Fonte:Elaborada pelos autores.

O curso foi organizado como uma possibilidade de problematizar e produzir uma reflexão sobre as prá-

${ }^{5}$ Devido a construção do Kamal ter sido feito pelo modelo português, não conseguimos aplicá-lo pois não podemos visualizar a estrela polar no nosso hemisfério. 
ticas de ensino desenvolvida pelos discentes no Núcleo de Formação Geral ou de Atividades Curriculares Complementares (ACC), uma vez que as diretrizes para a formação do professor preconizam que tal exigência seja incorporada às licenciaturas. A ACC deve ter pelo menos 200 horas para outras atividades acadêmico-científico-culturais, com vistas ao enriquecimento do processo formativo do professor como um todo, como reforça as diretrizes do Parecer № 9/2001.

\section{ANÁLISE DOS DADOS}

Com o intuito de realizar o tratamento dos dados coletados no curso, elaboraram-se quatro categorias de análise partindo das leituras de Saito e Dias (2011) e Saito (2016) desencadeada em três esferas de análise: Historiográfica, Epistemológica e Contextual. Dessa forma, as categorias escolhidas foram: a História da Matemática como recurso didático; conhecimento matemático para a construção do Kamal; possibilidade de inserção do Kamal na sala de aula da Educação Básica; e o instrumentos históricos de medição como uma ponte para unir a teoria e a prática matemática.

No pré-teste, conseguiu-se identificar que todos os participantes eram discentes do curso de licenciatura em Matemática da UECE e que aproximadamente $35 \%$ já atuavam como docente em instituições públicas e particulares da educação básica do Ceará.

Outro ponto observado no pré-teste foi a menção à utilização de recursos didáticos diferenciados (jogos, modelagem matemática, História da Matemática, resolução de problemas, etnomatemática, tecnologias, entre outros) nas suas salas de auld 6

Mais da metade dos participantes (56\%) afirmaram não terem sido incentivados pelos seus professores, no decorrer da formação, a fazer uso de recursos didáticos nas aulas e $44 \%$ afirmam que foram incentivados no uso de metodologias diferenciadas, no qual tiveram contato com alguns recursos didáticos, como: filmes, materiais manipuláveis, jogos e resoluções de problemas.

$\mathrm{Na}$ primeira categoria que se refere à História da Matemática como recurso didático percebeu-se positivamente a incorporação desse recurso na sala de aula da Educação Básica. Os participantes concordam que é uma "técnica" encantadora para o trabalho do professor e de grande importância, pois por meio da História da Matemática pode-se conhecer a origem de determinado conceito. Além disso, mencionaram que a História se apresenta como uma metodologia atrativa para as aulas

\footnotetext{
${ }^{6}$ Nesse ponto, consideram-se tanto os recursos que eles já utilizam como professores da educação básica como também os recursos que seus professores utilizam durante o curso de licenciatura em matemática.
}

de matemática, por possibilitar uma interação entre o passado e o presente. Isso pode ser percebido na fala de um dos participantes: "Conhecer a História da Matemática ajuda a desenvolver um maior interesse pela mesma, ampliando saberes que são aplicados na aprendizagem e no ensino da matemática”.

Com relação ao conhecimento matemático para a construção do Kamal percebeu-se, que as transformações de ângulos, de graus para minutos e segundos e posteriormente para isba foi um fator de dificuldade para os participantes. Isso por sua vez, nos levou a retomar os conceitos da educação básica para avançarmos na construção do Kamal. Outro ponto notado na construção do instrumento Kamal foi à marcação dos nós no cordel. Devido à exigência de certo grau de precisão dessa marcação, os participantes apresentaram dificuldades.

No que se refere à possibilidade de inserção do Kamal na sala de aula do Ensino Básico os participantes indicaram:

- A relação entre a História da Matemática e a composição do Kamal possibilita a compreensão da origem e da construção de determinados conceitos, além de "porquês" presentes nas salas de aulas;

- A confecção do instrumento permitiu uma maior interação entre professor/aluno/conteúdo;

- A construção do instrumento permitiu entrar em contato com ferramentas, como por exemplo, compasso, esquadro, transferidor e etc., que muitas vezes são esquecidas nos cursos superiores e poucas utilizadas no ensino básico;

- O uso do instrumento é um recurso diferenciado para abordar determinados conteúdos matemáticos, como por exemplo, a trigonometria no triângulo retângulo e as transformações de ângulos.

- A confecção do Kamal requer o uso de um material de baixo custo, o que viabiliza sua utilização em sala de aula;

- O professor torna as aulas mais atrativas devido à inserção do instrumento e à aplicação prática do conteúdo estudado em sala de aula.

A última categoria analisada foi pautada nos instrumentos históricos de medição como uma ponte para unir a teoria e prática matemática. Nesse quesito, notou-se que os participantes ressaltaram a construção do Kamal como um recurso possível de ser apresentado em sala, principalmente na visualização de um conteúdo estudado. A manipulação do objeto perpassa 
pelos conceitos estudados na sua confecção, além de mostrar o fazer matemática dos povos do passado relacionado com a atual concepção de ensino. Isso pode ser percebido na fala do um dos participantes:

"Através da construção do Kamal pude perceber quão grande é a extensão da matemática no cotidiano escolar e universitário. Mesmos necessitando de um conhecimento maior da área matemática, a construção do Kamal pode ser aplicada em diversos momentos de ensino, unificando a teoria com a prática”.

Em vista do que o participante mencionou, compreende-se que o emprego de certos instrumentos antigos de medida pode ser acrescentado às aulas de Matemática na forma de uma metodologia diferenciada, para o enfoque de conteúdos relacionados à Trigonometria e à Geometria. Ressalta-se que esse recurso didático oferece ao docente a liberdade de utilizála para abordar, inicialmente, um conteúdo ou, em um momento posterior, explorar um assunto já ministrado em sala de aula.

\section{Considerações finais}

O percurso acadêmico vivenciado como docente na formação inicial e continuada de professores de Matemática, tem-nos direcionado para a ampliação de estratégias de ensino significativas acerca da valorização de metodologias para abordar a Matemática da Educação Básica e Superior. Dentre elas, o uso da História da Matemática, é uma delas, pois, possibilita o enriquecimento do currículo dos cursos, bem como um novo olhar na estruturação do conhecimento matemático.

Nesse sentido, a seguir faz-se a exposição de constatações que foram no detectadas no decorrer do curso de extensão universitária sobre o Kamal:

- Os futuros docentes anseiam conhecer novos métodos e técnicas para ensinar matemática, contudo, durante sua formação, são apresentados poucos artifícios para o uso em sala de aula;

- Os instrumentos históricos de medida são uma ponte que conecta o uso de material manipulativo e História da Matemática;

- Ainda existem dificuldades conceituais nos conteúdos de Trigonometria e Geometria por parte dos futuros docentes;

- Os futuros docentes não sabem manipular entes do desenho geométrico, já que na sua formação essa disciplina não é obrigatória no currículo escolar;
- A construção do instrumento, a matemática envolvida e a aplicação permitiram uma integração dos futuros docentes, valorizando o trabalho em grupo.

Dentre essas observações, que manifestam as potencialidades do uso do Kamal como recurso didático, percebe-se que a sua não aplicação suscitou uma decepção por parte dos participantes como uma maneira de comprovar a importância do seu uso em sala de aula. Pois, embora, tenha sido ensinado como o Kamal possa ser utilizado, fomos impossibilitados de efetuar a medição, visto que a estrela polar não é vista no nosso hemisfério. Dessa forma, acredita-se que o espectro de formação do professor de Matemática também deve ser direcionado para ampliação da visão de conhecimentos que possam contribuir para melhoria do ensino da matemática.

\section{REFERÊNCIAS}

ALBUQUERQUE, L. M. de. Curso de História da Náutica. : Coimbra: Livraria Almedina, 1972.

BUSSI, M. G. B. Ancient instruments in the modern classroom.fauvel, john.; maanen, jan. van. (eds.). history in mathematics education: the icmi study. Dordrecht/Boston/London: Kluwer Academic Publishers, v. 6, p. 343-350, 2000.

FISHER, D. Latitude Books and Azimuth Kings: How To Build and Use 18 Traditional Navigational Tools. : Camden: Internacional Marine, 1994.

MENDES, I. A. A investigação histórica como agente da cognição matemática na sala de aula. in: Mendes, iran abreu; fossa, john a.; valdÉs, juan e. nápoles. (orgs.). A história como agente de cognição na Educação Matemática. Porto Alegre: Sulina, 2006.

PIMENTEL, M. A arte de navegar, lisboa. Lisboa: na Officina de Miguel Manescal da Costa, Impressor do Santo Officio., 1762.

PINTO, M. M. Os instrumentos náuticos de navegação e o ensino da geometria. Lisboa: Sociedade Portuguesa de Matemática, 2010.

RODRIGUES, A. F. F. Construção de um kamal, tavoletas da Índia ou balestilha do mouro. ano internacional da astronomia-2009. Universidade dos Açores. Angra do Heroísmo, 2009. Disponível em: <http://desambientado.blogspot.com.br/2009/ 11/astronomia-no-dia-dia-construcao-de-um.html> Acesso em: 22 jun. 2015. 
SAITO, F. Possíveis fontes para a história da matemática: Explorando os tratados que versam sobre construção e uso de instrumentos "matemáticos" do século xvi. in: Silva, m. r. b. da; haddad, t. a. s. (orgs.). Anais do 13 Seminário Nacional de História da Ciência e da Tecnologia - FFLCH USP - 03 a 06 de setembro de 2012. São Paulo: EACH/USP, p. 1099-1110, 2012.

Instrumentos e o"saber-fazer"matemático no século xvi. Revista Tecnologia e Sociedade, Curitiba, v. 18, n. especial, p. 101-112, 2013.

Instrumentos matemáticos dos séculos xvi e xvii na articulação entre história, ensino e aprendizagem de matemática. Rematec, Natal (RN), ano 9, n. 16, p. 25-47, mai-ago 2014

História e ensino de matemática: construindo interfaces.in: Jesús flores salazar e francisco ugarte guerra (eds.). investigaciones em educación matemática. Lima: Fondo Editorial PUCP, p. 253-291, 2016.

SAITO, F.; DIAS, M. d. S. Articulação de entes matemáticos na construção e utilização de instrumento de medida do século xvi. Natal: Sociedade Brasileira de História da Matemática, (Coleção História da Matemática para Professores), 2011.

SILVA, L. P. da. Kamal, tábuas da índia e tavoletas náuticas. Lusitania: revista de estudos portugueses, Coimbra, v. 1, n. 3, p. 362-371, jun 1924. 